\title{
Quinteto de Buenos Aires: La educación sentimental de Pe- pe Carvalho
}

WADDA C. RIOS FONT

Aunque la halles pobre, Itaca no te ha engañado. Así, sabio como te has vuelto, con tanta experiencia, entenderás ya qué significan las Itacas.

C. Cavafis, Ítaca

La novela Quinteto de Buenos Aires (1997), de Manuel Vázquez Montalbán, es larga, complicada, en apariencia hasta farragosa, y a pesar de ello es una de las más ambiciosas y profundas de la Serie Carvalho. El recuento de una verdadera odisea trasatlántica emprendida por el detective en busca, casi terapéutica y desde luego ética, de la recuperación de una memoria familiar e histórica se convierte en un intrincado ejercicio no de reconciliación, sino de conciliación. La investigación de ciertas desapariciones que realiza el detective español Pepe Carvalho en Argentina no tiene como resultado el esclarecimiento literal o simbólico de ningún misterio; tampoco, en consecuencia, se hace justicia, ni se restaura ningún orden moral aunque sea alternativo al aceptado oficialmente, ni se supera ningún pacto de olvido. Si bien se da por descontado que tanto en la dictadura española como en la argentina-holocaustos paralelos-hubo víctimas y victimarios, y por supuesto no se equiparan falsamente bandos opuestos bajo una supuesta culpabilidad compartida, desde la óptica de esta novela escrita al final de la década de los noventa ya es casi irrelevante distinguir quién debe ser castigado y a quién se le debe reparación. En las nuevas democracias neoliberales de alcance global el poder de siempre se oculta a la vez que se repite y transforma incesantemente; por ello pierden cierto sentido precisamente conceptos como "memoria" o "recuperación" que implican alguna negociación curativa con el pasado. Lo que queda es acatar la pérdida e instalarse en la tragedia, conciliar la pureza teórica de la víctima con la impureza real de los supervivientes y tratar de inventar-firmemente en el presente-nuevas formas de resistencia inevitablemente parciales.

Esta visión se trasluce a través de técnicas diegéticas y estructurales. En un primer nivel, la revisión de las convenciones de la novela negra presente en la serie desde sus comienzos adquiere mayor relieve. Aunque 
el Carvalho detective/investigador siempre estuvo apartado de la ley y el orden institucionales, especialmente en tanto éstos corresponden a turbios intereses políticos y económicos, en Quinteto no sólo se desdibuja esta oposición sino que el protagonista se aleja cada vez más de modelos tradicionales del detective como inteligencia superior y encarnación de la racionalidad. Además de no investigar el caso que le fue encomendado, lo cual en sí tampoco es nada nuevo, no tiene gran éxito en resolver los casos que sí le preocupan. Ello ocurre porque se muestra incapaz de mantener distancia alguna con respecto a los implicados, hallándose él mismo cada vez más ligado a los demás personajes de formas diversas, algunas anticipadas y otras realmente imprevistas. En efecto, su sagacidad deductiva da paso a una emocionalidad avasalladora, y experimenta una auténtica educación sentimental que le lleva a formas de conocimiento inesperadamente intuitivas. El mundo al cual ha llegado Carvalho ya no es ni el del positivismo decimonónico en que se originó el género ni el de la transición española en que nació esta serie, y no admite siquiera las insuficientes certezas y garantías que aún daban sentido a la función del detective. En un segundo nivel, la construcción novelística refuerza esta trayectoria de lo intelectual a lo emocional. De Quinteto han desaparecido casi totalmente la omnisciencia, la perspectiva en pasado y el discurso indirecto libre hasta entonces predominantes en la serie, y que daban al lector acceso al razonamiento de Carvalho. En su lugar aparecen un argumento lleno de entrecruzamientos y reduplicaciones entre situaciones y personajes (Carvalho incluído); un complejo entramado de relaciones intertextuales (muchas de ellas con motivos de la propia obra de Vázquez Montalbán que también conforman un universo afectivo del autor); y una estructura cuasi-musical en la cual el argumento sigue una lógica menos expositiva que compositiva, a la vez que un conjunto de canciones sentimentales sirve de guía a la acción. Técnicas como éstas provocan - en Carvalho y posiblemente también en los lectores - una catarsis puramente emocional, sin recurso a la razón ni vuelta a la armonía. Todo el aparato novelístico puede interpretarse desde postulados de la teoría e historia de las emociones como los de Monique Scheer o Walter Reddy, que contemplan la subversión de formas sancionadas de sentir como práctica social efectiva capaz de alterar, al menos circunstancialmente, los efectos de regímenes represivos sustentados en gran parte mediante la regulación de lo afectivo. 
Al principio de la novela Don Evaristo, el tío de América, le pide a Pepe Carvalho que vaya a Buenos Aires para buscar a su hijo Raúl Tourón, a quien había rescatado de los militares y traído a España veinte años antes, y cuyo paradero se desconoce desde que se marchó de vuelta a intentar encontrar a su hija desaparecida. A punto de quemar una guía turística de la ciudad, Carvalho inesperadamente la indulta del fuego porque puede servirle para preparar su viaje: “¿Qué sabes tú de Buenos Aires? Tango, Desaparecidos, Maradona". La novela no es Quinteto de Buenos Aires, en la cual Carvalho emprenderá esta misión, sino un volumen anterior de la serie detectivesca, El premio (1996). Carvalho evoca el tango "A media luz" y parece contrastar el "crepúsculo interior" de sus versos con el vacío de su propia casa: "Cada vez que la palabra amor aparecía en el techo de aquel su destartalado y descuidado living, se le venía encima como una lámpara de goznes oxidados y cansada ya de no dar luz" (Premio 62). Afectado por "la soledad" debida a la ausencia de su novia Charo (que se ha ido a Andorra agotada por su desamor), parece a punto de permitirse una muy poco característica melancolía cuando le sorprende su ayudante Biscuter anunciándole un nuevo e irresistible caso: "Le ponen un avión en El Prat, y de momento le pagan doscientas mil" (63). Toda la novela El premio, cuya acción transcurre en pocos días, es una doble interrupción: demora el comienzo de la investigación encargada por el tío y corta de raíz la introspección nostálgica en que se disponía a sumergirse el detective, desviándolo hacia el tono muy distinto de una metaficción paródica. A su vez, Quinteto de Buenos Aires nace como desdoblamiento de la novela anterior-el primero de muchos engarces con el resto de la obra de Vázquez Montalbán que convertirán esta novela en un verdadero mapa de evocaciones igualmente nostálgicas.

La misma entrevista con el tío reaparece al comienzo de Quinteto, con un cambio sugerente. En la primera novela se narraba en una combinación de tercera persona omnisciente y estilo indirecto libre, y en tiempo pasado:

Recordaba el mandato de su tío, sentado el anciano en un sillón Emmanue1le... "Estoy en manos de sobrinas... no quiero que esos cuervos se lleven lo que pertenece a mi hijo.Tú, tú puedes encontrarlo. Sabes cómo hacerlo, ¿no eres policía?" "Detective privado", contestó Carvalho e incluso se oyó a sí mismo tratando de explicarle al viejo la diferencia entre un policía y un detective privado. (Premio 61, énfasis añadido) 
En esta perspectiva, la que domina esta novela y la mayor parte de la serie de Vázquez Montalbán hasta el momento, el narrador omnisciente cuenta, describe, contextualiza y explica toda la aventura; además, su uso del tiempo pasado presenta el caso como otro más cerrado por el detective, por muy a su manera que lo haga. El discurso indirecto libre provee acceso a los procesos mentales y la particular (y privilegiada) óptica del investigador, siempre foco de interés especial en el género detectivesco. Ese recurso estilístico con frecuencia nos refiere un diálogo interior de Carvalho consigo mismo en el cual no sólo vive las circunstancias en que se encuentra, sino que simultáneamente las observa y analiza desde fuera. Como en el pasaje citado, incluso hasta se oye desde fuera a sí mismo, técnica que aunque nos acerca como lectores al detective, también lo aísla a él de todo y todos a su alrededor. La proverbial actitud indiferente y distante de Carvalho, aunque en los argumentos sea su reacción a un mundo con el cual cada vez encuentra menor conexión, es en gran medida efecto de este marco narrativo.

En Quinteto de Buenos Aires la entrevista con el viejo Tourón aparece como diálogo interrumpido en algunas, pocas, ocasiones por una voz narrativa cuya función es sobre todo descriptiva. El punto de vista temporal es ahora el presente:

- ¿Qué sabes tú de Buenos Aires?

Ni pesimista ni optimista, la voz de Carvalho le contesta:

-Tango, desaparecidos, Maradona.

El viejo cabecea más pesimista todavía y repite:

-Tango, desaparecidos, Maradona.

Ante Carvalho la perspectiva de un terrado barcelonés, el viejo sentado en un sillón, en el horizonte la ciudad como si creciera a medida que se la mira...

-Estoy en manos de sobrinas. No quiero que esos cuervos se lleven lo que pertenece a mi hijo...Tú, tú puedes encontrarlo. Sabes cómo hacerlo, ¿no eres policía?

-Detective privado.

- ¿No es lo mismo?

-La policía garantiza el orden. Yo me limito a descubrir el desorden.

Carvalho se levanta, camina hasta la baranda de la terraza y recibe de la ciudad una propuesta síntesis de la vieja y la nueva Barcelona Olímpica. (1011) 
Este cambio estilístico, prevalente en la nueva novela, en teoría obedece a que ésta se basa en libretos inicialmente escritos para una fracasada teleserie. Como nos recuerda José Colmeiro, "el colapso del proyecto televisivo llevó al autor a desarrollar en forma narrativa los guiones ya escritos previamente" (275). De forma parecida a las acotaciones de un guión, la voz narrativa de Quinteto de Buenos Aires-que suele aparecer en oraciones intercaladas y casi nunca se extiende más de un par de párrafos-describe las diferentes escenas como para potenciales espectadores. Se suprime casi del todo (aunque en ocasiones selectas reaparece) el discurso indirecto libre que nos acercaba al pensamiento de Carvalho, reteniéndose sólo la suficiente omnisciencia como para indicar a un hipotético director o actores cómo representar los personajes. Incluso en las breves vueltas al discurso indirecto, los sentimientos de los personajes aparecen ligados frecuentemente a una descripción visual externa: "El rostro de Carvalho está de luto y hasta siente niebla almacenada en la recámara de los ojos" (382). Los ojos, como órganos tanto del ver/descubrir detectivesco como del llorar, serán una imagen frecuentísima en el texto. El punto de vista en el presente se quiebra, si mi cuenta es exacta, sólo en dos momentos. Primero, cuando Carvalho todavía está en Barcelona y se menciona que "no se reconocía en la ciudad" (16). Y por segunda vez dentro de un raro monólogo interior que no es de Carvalho sino de Raúl, recordando su prisión durante el Proceso: "Los torturadores de pronto te sacaban de la caverna a donde sólo te llegaban las sombras de la realidad" (49).

En su conjunto, Quinteto de Buenos Aires invierte la organización narrativa de las novelas anteriores: se cierra para los lectores buena parte del acceso al razonamiento de Carvalho, mientras que la inmediatez temporal y el énfasis en la descripción visual de escenas, movimientos y gestos dirigen la atención al espacio en que se mueve. Por supuesto, en referencia a este cambio estilístico puede hacerse la crítica obvia: Vázquez Montalbán hizo un muy pragmático "corta y pega" de segmentos escritos para la teleserie y segmentos escritos para su novelización. Pero el autor, poeta experimentado y veterano de varios géneros literarios, fue siempre sumamente consciente del estilo. Es de asumir, por lo tanto, que su decisión de incorporar el punto de vista de la serie audiovisual a la serie narrativa obedece a la búsqueda deliberada de un nuevo efecto. La técnica resultante frustra expectativas de lectura y delinea para el público un Carvalho algo diferente al que ya conoce. Después del paréntesis metaficticio (y por tanto hiperdistanciado) abierto por El premio, Carvalho vuelve al momento de la experiencia emocional interrumpida. 
Quinteto de Buenos Aires constituirá esa experiencia emocional y el mencionado cambio narrativo es el primero de muchos recursos estilísticos que funcionarán para dar idea a los lectores-espectadores de la transformación sufrida por el protagonista durante una investigación que finalmente lo enfrenta a los límites de la recuperación de la memoria.

Es bien conocida la insistencia de Vázquez Montalbán en la diferencia entre los protagonistas de la detectivesca convencional y el personaje de Carvalho, cuya visión comporta mayor complejidad moral y mayor crítica de un orden establecido que finalmente no defiende. A pesar de estas profesadas diferencias, las novelas de Carvalho mantienen siempre elementos clave tanto de la novela-enigma clásica como de la novela negra, y uno de éstos es el tronco intelectual del detective. Desde el mismísimo Sherlock Holmes, por dar el ejemplo arquetípico, el investigador es sobre todo epítome de la racionalidad. En A Study in Scarlet (1887), la primera historia donde aparece el personaje, Arthur Conan Doyle describe ya al "consulting detective" (28) ante todo como "logician" (26), y su quehacer como "the science of deduction and analysis" (26). El funcionamiento de su cerebro analítico fascina de inmediato al Dr. John H. Watson, que incluso esboza un bosquejo de los contenidos de su mente, convirtiendo la misma en un objeto de indagación tan fascinante (para él y para los lectores) como los crímenes que Holmes investigará. El énfasis en la racionalidad lleva consigo la eliminación de lo emocional. Todavía en "The Simple Art of Murder" (1939) Raymond Chandler considera la detectivesca esencialmente "a problem of logic and deduction" (524). Apunta dos veces como característica sine qua non de los detectives (y de paso, de los escritores) una actitud cerebral y, si bien no insensible, ciertamente impasible: un "spirit of detachment" $(520,532)$. Fiel en este aspecto a los modelos, a lo largo de la serie de Vázquez Montalbán tanto los afectos de Carvalho (por Charo, por Biscuter, por Fuster) como su empatía por las víctimas aparecen restringidos por límites estrictos, muchas veces autoimpuestos.

En Quinteto de Buenos Aires desde el primer momento múltiples correspondencias - Carvalho y su primo Raúl, el tío y el padre, Alma y Charo, don Vito y Biscuter, y por supuesto los regímenes español y argentino - amenazan con destruir la perspectiva objetiva del detective modélico. Ya el vocabulario del encargo del tío establece el primer encadenamiento que implica personalmente a Carvalho: "Por la memoria de tu padre, sobrino, vete a Buenos Aires. Busca a mi hijo, a mi Raúl" (10). Mi hijo, tu padre: el investigador (sobrino) se convierte en vértice de dos familias y dos circunstancias históricas, por lo cual la pesquisa será tam- 
bién una indagación en su propio pasado. En consecuencia, el tema del regreso simbólico se repite numerosas veces. A medida que Carvalho intima con Alma, la antigua esposa de Raúl y madre de la niña desaparecida, ella le plantea que "tenés cara de hombre que tiene miedo de no poder volver a casa" (180). Carvalho le contesta que "nunca he vuelto a casa. Y lo malo es que no recuerdo el momento en que me marché, ni de qué casa". Su habitual sentimiento de desconexión (perenne dentro de toda la serie y aún vestigial en Quinteto) — “aún no he llegado a ningún lugar del que no quiera marcharme" (128)—alterna aquí con una nostalgia de lo irrecuperable. Así, por ejemplo, reformula el planteamiento de don Evaristo asociando la patria perdida con la madre: "Era la posguerra en Barcelona... Una mañana mi madre me dio un pedazo de pan que parecía recién hecho... y un puñado de aceitunas negras, muy sabrosas...Recuerdo aquellos sabores, la alegría de mi libertad en la calle... Si pudiera volver a aquella mañana. Ésa sería mi verdadera patria. Mi Rosebud" (390). La alusión al Rosebud de la película Citizen Kane (1941) de Orson Welles (motivo que se repite en el poemario póstumo de Vázquez Montalbán del mismo título publicado en su Poesía completa de 2008) recuerda el alcance que tenía en la historia del magnate Charles Foster Kane el trineo de su niñez que llevaba ese nombre. Según el crítico de cine Peter Bradshaw, Rosebud se ha visto como "the anti-riddle of the anti-Sphinx... the film's teasing offer of synechdoche: the part for the whole, the one jigsaw piece that is in fact the whole puzzle... [It] is more probably Welles's intuition of the flashback effect of memory... The remembered details of early existence...have an arbitrary poetic authenticity... the rational understanding of which would rob them of their mysterious force." La investigación que pone en marcha don Evaristo Tourón conecta, como el trineo de la película, un origen afectivo y privado con una saga política y pública. Para Carvalho, será una búsqueda infructuosa de significado y un encuentro con la nulidad (o tal vez la circularidad) de la memoria y del linaje - un proyecto en que cualquier solución racional anularía precisamente la fuerza generativa del misterio y que sólo permite ser abordado desde la arbitrariedad poética del sentimiento. Como Citizen Kane, Quinteto será una obra fragmentada y de interpretación difícil; fiel a su inspiración cinematográfica, retendrá también en gran medida las cualidades de un libreto.

Las numerosísimas "acotaciones" de la novela hacen constar la implicación personal de Carvalho en esta investigación. Aún la lectura más superficial de los insertos narrativos nos muestra una sucesión de reacciones emotivas que casi constituyen una pantomima melodramática. En 
una escena que enlaza con el principio de El premio, al llegar a Buenos Aires, "la capital del sentimiento" (Quinteto 23), Carvalho le pide a Alma una "concesión sentimental": la visita antes que nada a la calle Corrientes donde, como todos los demás turistas, se sorprende al hallar sólo "un desolado parking" (24). Será el primero de los muchos "vacíos" (467) que identifica como el rasgo argentino que más lo impresiona—un vacío donde previsiblemente al final de la novela aparecerá un cadáver. Inaugurada la aventura con esta decepción, la novela-guión comienza a narrar la pesquisa de Carvalho a través de una serie de escenas en las cuales se destaca la larguísima sucesión de los estados de ánimo que lo acometen. Actúa en diferentes momentos con "compasión" (102), "estupefacción" o "ternura" (105); "emocionado" (125), "cansado" (117), "airado, histérico" (141), "escéptico" (311), "melancólico" y "meditabundo" (320), "hastiado" (321), "temeroso" (337), "cauteloso" (341), "sorprendido" (326) - a veces "ante su propio aspecto" (305) — tal vez "con cara de póquer" (118) o con "asombro" (137), con "desasosiego" (187), "suspirando" (355) o con una "fruncida de ceño" (415). Vemos cuando muestra "un rostro impenetrable que no quiere traducir ninguna emoción" (62), "se encoge de hombros" (253) o "da media vuelta" (420). Cuando escucha a la tanguista Adriana Varela, a quien no puede evitar comerse con los ojos, aparece "alelado" $(125,201)$. Si llama a Biscuter y no recibe noticias de Charo, lo notamos "empequeñecido...[por] una inabarcable sensación de soledad" (168), o absorto contemplando un fuego que le "ilumina las melancolías" (389). Aún sin prestar atención a las causas específicas de sus humores, queda claro que Vázquez Montalbán ha organizado un verdadero despliegue que nos alerta a las formas en que el descubrimiento y la comprensión en esta novela van unidos a procesos afectivos. Y las reacciones de Carvalho no son simplemente respuestas aleatorias a la secuencia de situaciones en que se encuentra, sino que configuran precisamente un desarrollo emocional. Nada más iniciar sus averiguaciones en Nueva Argentinidad, los laboratorios donde se explotan los descubrimientos sobre el comportamiento de las ratas bajo tortura que le fueron robados a Raúl Tourón, todavía "los ojos interiores de Carvalho tratan de distanciarse" (45), en una nueva referencia a la importancia de los ojos de Carvalho en la representación de su emotividad. Pero la avalancha de sensaciones que experimenta le impone la conciencia creciente de que no puede mantenerse en el terreno neutral, y por lo tanto seguro, del detective clásico.

Tal vez la primera ocasión en que Carvalho pierde su arquetípico distanciamiento es la visita a las oficinas de las abuelas de la Plaza de Ma- 
yo. Poco antes Alma le ha contado la historia de la noche en que los militares la detuvieron junto con Raúl y su cuadrilla de compañeros "subversivos": Norman, Pignatari, Güelmes, Font y Rius, otros "que no vivieron para contarlo" (55). Cuando Berta, hermana de Alma y líder del grupo, se aprestaba impulsivamente a hacerles frente con una pistola, Raúl le gritó: “¡No seas boluda que nos van a matar la nena! ¡Nos rendimos! A cambio de la vida de la nena" (56). Alma entonces escapó con la bebé, que le fue arrebatada más tarde. No se revela en ese momentosólo se hará explícito muchas páginas después (102) —el detalle crucial de que la verdadera Alma, hermana de Berta y esposa de Font y Riusmurió esa noche, y que la actual Alma es realmente Berta, que la ha podido suplantar gracias al enorme parecido físico entre las dos. Las pistas, sin embargo, están ahí, y sólo la supresión del discurso indirecto libre oculta al público (al menos en una primera lectura) que Carvalho ha entendido, o al menos intuido, lo no dicho. Al comenzar su relato, Alma "interpreta diferentes papeles de los que intervinieron aquella noche" (55, énfasis añadido). Cuando habla de Font y Rius, repite dos veces la relación entre ellos, como para insistir en algo que sabe falso: "Font y Rius, mi marido, sí, mi marido". El texto que sigue inmediatamente al momento en que Raúl le grita a Berta que tienen que rendirse dice que "dejé la pistola...Salí con mi Eva María" (56, énfasis añadidos). Y acto seguido Carvalho tiene que aquietar físicamente "el balanceo acunador de su brazo".

Cuando en la escena siguiente el detective sigue la pista de Eva María Tourón Modotti en el local de las madres su pretendida ironía le falla, no sólo por el evidente pathos del lugar, sino porque sabe que busca a la hija de Alma. Volviendo momentáneamente a contar desde su punto de vista, la voz narrativa apunta que "todo el que penetra en el local entrega y recibe una invisible tarjeta de crédito ético, un Master Card de solidaridad. Lo nota Carvalho en el bolsillo de la chaqueta situado sobre el corazón" (57). Cuando la vieja recepcionista de "ojos insuficientes y oceánicos" (58) que rezonga constantemente por "la humedad" (57) le comenta que "a veces estamos ciegos ante lo evidente" (58), Carvalho le responde con su habitual "sonrisa irónica" (59). Sin embargo, al terminar la entrevista su fisonomía recuerda la de la empleada, con "ojos tan llenos de humedad que temió reconocerse a sí mismo que estaba llorando".

Carvalho trata de aferrarse a la distancia racional en la que siempre se ha situado, pero a medida que la investigación avanza se va encontrando más metido en la trama argentina, cuyos protagonistas empiezan a solaparse con los de su vida en Barcelona. Hacerse amante de Alma (Berta) 
refuerza la conexión con su primo Raúl ya establecida desde el encargo de don Evaristo. Y empiezan también a aparecer asociadas Alma y Charo: será la primera quien no sólo ocupará la cama y los afectos de Carvalho en Buenos Aires, sino que eventualmente podrá leer la carta que él constantemente reescribe pero nunca envía a la segunda. Cuando por primera vez Biscuter le cuenta por teléfono a Carvalho que Charo finalmente ha llamado y "dijo que usted era el hombre de su vida" (258), el detective reacciona a la noticia que esperaba (con tanto deseo como ambivalencia) lanzándose, momentos después, a un encuentro sexual con Alma que no tiene nada de casual: "ha sido amor, teme Carvalho" (262). No se trata de un reemplazo, sino de una imbricación de personajes. Pronto la relación sentimental llega a convertirse en un cuarteto casi coreografiado en el que a veces están presentes de alguna manera todos los integrantes:

Carvalho frente a la hoguera, de espaldas a Raúl y Alma. La mujer se le acerca por detrás, le rodea el cuello con los brazos y pone la barbilla sobre su cabeza.

- ¿Ha llamado tu Charo? La gaita esa.

- Casi no ha preguntado por mí.

- Una zorra como todas las mujeres. Únicamente piensa en vos y por eso ni siquiera te menciona.

Abandona a Carvalho. Mira ahora hacia Raúl, deprimido, luego a Carvalho... Alma, Raúl y Carvalho están vestidos, tumbados en la cama sin abrir. (389)

Al preguntar Carvalho tras unos segundos "¿por qué no te vuelves a España conmigo?", lingüísticamente no queda claro si se lo pregunta al primo a quien ha venido a buscar, a Alma a quien ha empezado a acercarse, o a Charo en su exilio de Andorra.

La implicación emocional del investigador en el marco argentino no se limita a su relación con Alma y Raúl. Seguir el rastro del primo-a quien encuentra y deja escapar varias veces - supone ir conociendo a los amigos con quienes éste compartió su militancia y a quienes ha buscado a su regreso. En particular, Carvalho tiene que interactuar con los miembros tercero y cuarto del antiguo quinteto: el psicólogo argentino Font y Rius, que al principio parece un burgués que ha adoptado sin mayor problema el "posibilismo" (461) de asociarse económicamente a su antiguo torturador (el Capitán) en el proyecto Nueva Argentinidad, y al final concluye que "no hay otra victoria que destruir a los capitanes"; y Norman Silverstein, el antiguo arquitecto que luchaba "por insensatez" y terminó como actor de dramas irrepresentables que ponen en escena una 
y otra vez su impotencia figurada y literal. El quinto de los antiguos compañeros, Güelmes, es ahora Ministro de Fomento y ha traspasado de manera significativa la raya que los separaba del poder. Será él, como se verá, uno de los que moverá los hilos para que Raúl y Carvalho identifiquen y encuentren a la hija perdida. (La configuración del quinteto, como tantas otras cosas en la novela, fluctúa dependiendo de si se incluye a Alma, Raúl o Carvalho; como se ha visto antes, los presentes la noche del arresto eran siete, además posiblemente de "otros" no identificados 55). Con Güelmes del otro lado, es Carvalho el quinto mosquetero, y le cae encima la experiencia de los otros. Así, al acudir con Norman a recoger a Alma después de ser agredida humillantemente por los hombres del Capitán, se enfrenta a su propia incapacidad de permanecer fuera del conflicto. En la comisaría maldice "las circunstancias que le han llevado a Buenos Aires y a esa sensación de complicidad con estos residuos humanos e históricos, y se repite los adjetivos con rencor y compasión mientras contempla la Piedad que componen Silverstein y Alma" (240). Más adelante, después de contar a su ayudante Don Vito que sabe que la alumna de Alma, Muriel, es en realidad su hija Eva María y que fue adoptada por el mismo Capitán, le ordena seguirla "y al hacerlo se reconoce afectado sentimentalmente, como si estuviera describiendo a un personaje muy especial de su propia familia" (425) - circunstancia efectivamente cierta. De esta manera, Carvalho pasa de la compasión y la complicidad a la identidad. Sólo al concluir el caso, con Raúl y su hija localizados, vuelve a salir del círculo: "Por fin Carvalho ha adquirido la condición de extraño al grupo y en su seno ha nacido un proyecto que sólo les pertenece a ellos" (504).

$¿$ Resuelve Carvalho el misterio? Es de notar que una y otra vez el detective gallego-catalán deja de dar pasos decisivos para resolver el caso que se le ha confiado. Muy pronto abandona la misión de encontrar a Raúl, vislumbrando (aunque sin expresarlo) que su desaparición voluntaria del ámbito de don Evaristo no es la auténtica desaparición que demanda ser investigada. En un momento dado se deja agredir por la policía para permitirle escapar -"los policías apuntan [a Raúl] con sus ametralladoras. Carvalho finge perder el equilibrio, cae sobre ellos y recibe un culatazo" (119)- y a lo largo de la novela lo sigue no para llevarlo de regreso a España sino para protegerlo y facilitar su búsqueda de la niña. No obstante, Carvalho parece huir por buen tiempo de las pistas sobre Alma y la niña, retrasando la solución de ese enigma. Ya se ha mencionado cómo al escuchar el primer recuento de la noche del arresto, el detective detiene el instintivo gesto maternal con que Alma acuna a la 
hija que recuerda. Detiene también el hilo mismo de ese recuerdo-_"por hoy ya está bien" (56) - una acción desconcertante en quien se supone inmerso en un ejercicio de recuperación de la memoria histórica. Algo más adelante, vuelve a sugerirse que tiene un conocimiento del que no se da cuenta explícita. Alma plantea, en conversación con Carvalho y Norman, que Raúl intentará ver a los demás amigos:

$-i$ A ti no?

Alma no le aguanta bien la mirada a Carvalho. Ella y Norman se miran, como propietarios de una secreta complicidad. Es Norman quien encuentra primero una respuesta.

-A Alma no conviene que la vea. Se parece demasiado a Berta.

Pero Carvalho sólo tiene ojos para el rostro conmovido de Alma y oídos para lo que la mujer no llega a decir. (73)

Dada la insinuación de que el detective comprende lo que su amiga no dice, sorprende su reacción subsiguiente cuando ella finalmente le revela su identidad, en una nueva versión de la historia que le contó anteriormente:

- ¿Me dirás de una vez por todas la verdad?

- La verdad no la sé. No me quedan verdades. Te puedo decir la mía. Te conté lo que pasó la noche del allanamiento. No. No fue como te lo conté...Ante todo yo no soy Alma. Yo soy Berta.

Carvalho ni quiere ni puede evitar su estupefacción. (102, énfasis añadido)

Estupefacción: asombro (como si no tuviera ya esta información), pero también parálisis. Aquí y a lo largo del argumento Carvalho postergará repetidamente la acción, evitando llegar a una resolución formal antes de culminar el proceso emotivo por el cual atraviesa.

Esta nueva versión de los hechos, otra de las varias reduplicaciones y reiteraciones históricas de la novela, reformula el mismo lenguaje de la primera versión, de forma parecida a lo que ocurre con el encargo del tío entre El premio y Quinteto: "Y por sus ojos más internos pasa la secuencia que sus palabras transcriben interpretando distintos personajes: Raúl me gritó desde la otra habitación. ¡No te hagás la boluda!... Alma se levantó para agarrar a la bebita y una ráfaga de ametralladora la mató...El cadáver de Alma, yo y Font y Rius, el marido de Alma...Mi cuñado me gritó. ¡Agarrá a la nena y escapate por el baño!” (102, énfasis añadidos). En este caso, la reescritura altera la heroicidad relativa de los personajes. La actual Alma, madre real de Eva María, revela cómo la verdadera (su 
tía) murió intentando salvarla mientras ella se enfrentaba a los militares, y es Font y Rius (uno de los personajes más moralmente sospechosos veinte años después) quien concibe el cambio de identidades para que Berta pueda huir con la niña. Tales desplazamientos dificultan la posibilidad de asignar un valor ético exacto a cada personaje - algo que tendrá cada vez mayor importancia en la novela.

La "parálisis" de Carvalho lo lleva a desviarse constantemente de la línea directa que habría de seguir en su investigación. De ahí, por ejemplo, que se asocie con Don Vito Altofini-su Biscuter americano-y acepte varios casos intercalados: el del "hombre oculto" (139), en lenguaje tanguero, acusado de haber matado a su novia (también Raúl se describe en la novela como "hombre oculto" $[150,157])$; el de la "mala mujer" (270) a quien recuerda haber ya encontrado en un caso barcelonés casi idéntico al de ahora; el del supuesto hijo natural de Jorge Luis Borges, amenazado por una sociedad llamada El Aleph cuyo club Carvalho acaba incendiando cuando Altofini es víctima allí de una terrible paliza; el del drogadicto desaparecido Loaiza (antiguo amante secreto del boxeador Bum Bum Peretti), que finalmente resulta ser colaborador del Capitán; y finalmente el del músico judío Abraham Gratowsky encontrado muerto en Corrientes 348, que Carvalho decide dejar en manos de Altofini para volverse a Barcelona. Todos estos casos se superpondrán y entrecruzarán no sólo entre ellos y con investigaciones anteriores de Carvalho en España, sino con la pesquisa sobre Raúl y su hija, dando así la impresión de que todos los crímenes cometidos en los dos espacios de referencia a ambos lados del Atlántico forman parte de una sola red. Como se hará evidente, su interrelación es de por sí significativa, pero lo que interesa destacar ahora es cómo sirven de digresiones y aplazamientos en el progreso lineal de la investigación Tourón-Modotti. Sabiendo todo lo que sabe, Carvalho cambia repetidas veces de dirección, y cerca del final de la novela él mismo explica la razón: "De hecho creo que no he tenido ganas de saber la verdad porque no tenía ganas de volver a España" (424). Tal vez sea la primera vez que no tiene ganas de marcharse.

Al pensar en el papel que tiene Carvalho en la solución del misterio, es de notar además que es sólo uno de tres investigadores centrales, junto a Raúl y el dúo de policías Pascuali-Vladimiro. En tanto eco de la búsqueda de Raúl, en sí misma vacilante y caótica, es inevitable que la de Carvalho también pierda periódicamente su norte. Como observa muy pronto Font y Rius, "creo que [Raúl] lloraba por sí mismo. Aunque a veces parecía llorar por la nena" (36). Ya en su primera conversación Alma y Raúl confrontan, no la duda-porque ambos están seguros de la 
necesidad que los impele - pero sí el carácter y sentido de esa misma necesidad:

-De vez en cuando veo a una chica por la calle y algo me dice: tu hija sería parecida a ella y me echo a llorar por dentro...A veces, pienso: no querés encontrarla, lo que querés es joder al que te la quitó.

-A mí me pasa algo parecido. ¿Me escondo porque me persiguen o porque únicamente puedo vivir escondido? (149)

Aunque Alma experimenta una confusión análoga, es significativo que Raúl, y con él Carvalho-los personajes explícitamente partícipes en la búsqueda comisionada por don Evaristo "en nombre del padre" y para quienes la investigación del paradero de Eva María se planteaba como una recuperación de la memoria-pierdan el hilo en ese laberinto hasta no estar seguros ya ni de sus propios motivos ni de qué intentan restaurar. Van dándose cuenta, en apariencia, de que su vuelta a casa sólo puede ser mítica. Así se lo confirma a Raúl "Borges Jr.", a quien conoce por casualidad en un banco de algún parque: "Mi padre, como yo, como todos, se inventó un regreso a casa. Pero cuando se vuelve, ni Penélope, ni Telémaco existen o son como deberían ser" (406). Se hace aquí la conexión directa entre Raúl y Ulises; que como se verá más adelante se repite también en relación a Carvalho. Pero la novela también está llena de otras conexiones intertextuales para indicar el colapso de un tiempo lineal susceptible de superaciones y enmiendas que permitan la transformación de una búsqueda (search) en empresa épica (quest). Así también vemos el Carvalho-Charlie Kane y el Raúl "Peter Pan" (108, 404). Y tanto al boxeador Peretti como a su antiguo profesor y amante Loaiza (ninguno de los cuales podía soportar la idea de recibir golpes en la cara) se les aplica el denominador de "Dorian Gray" (291, 350, 396).

Tan sugerentes como la conexión entre Carvalho y Raúl son sus paralelos con los policías argentinos. Desde el principio tanto de Quinteto de Buenos Aires como de El premio Carvalho enfatiza la distinción, tradicional en gran parte de la detectivesca y definitoria en la serie que protagoniza, entre el detective privado y el policía, como ya se ha visto: "La policía garantiza el orden. Yo me limito a descubrir el desorden". La típica rivalidad entre las dos figuras hace su aparición casi inmediatamente después del aterrizaje de Carvalho en Buenos Aires. Carvalho y Óscar Pascuali discuten más de una vez sus relativos méritos: "[Pascuali:] -Yo soy el futuro, la única posibilidad de orden. [Carvalho:] También la policía privada. -¿Usted? -No. Yo soy el último mohicano. Me refiero a la que está y estará al servicio del orden...Yo soy desorden" 
(334). Hay momentos, incluso, en que Pascuali y sus agentes golpean a Carvalho (como en el pasaje del culatazo mencionado) o insisten en que se vaya de la Argentina, y hasta llega a ser arrestado. Más allá de esta oposición, sin embargo, los dos personajes comienzan a duplicarse progresivamente. Su conexión se hace mayor a medida que Pascuali se va dando cuenta de que nunca podrá garantizar el orden en una democracia neoliberal orquestada en la cual los distintos actores ideológicos simplemente se realinean según lo requieren las circunstancias fluctuantes del nuevo estado corporativo. Lo que los acerca más es que Pascuali experimenta una evolución similar a la de Carvalho, desde sus orígenes como miembro de "la raza de policías sarcásticos" (60) hasta que, al despedirse emotivamente del español al final de la novela, "se lleva dos dedos a una supuesta visera y se retira dándole la espalda" (521). Carvalho, por su parte, lo mira entonces con "una frialdad que no siente" (520), y son sus gestos (y no, digamos, los de Alma) los que "conserva en la inmediata memoria durante el trayecto hasta la primera escala en Río de Janeiro" (521).

En consecuencia, algunas escenas protagonizadas por Pascuali calcan muy de cerca otras protagonizadas por Carvalho - otra instancia más de las duplicaciones tan frecuentes en Quinteto. Un ejemplo de muchos son las similaridades entre la secuencia que sigue y la ya citada en la cual Carvalho se entera de la verdadera identidad de Alma. En este caso, Pascuali es uno de los presentes en el momento en que Raúl ve por primera vez a Alma y se da cuenta de que en realidad es Berta. Como Carvalho, aunque escucha la explicación del parecido entre las hermanas parece darse cuenta de la historia no contada. Ambas escenas culminan con la reacción del investigador correspondiente, y al sobrecogimiento de Carvalho corresponde el de Pascuali:

Pascuali está muy nervioso...[Raúl] mira a todo el mundo, su rostro refleja distintas expresiones hasta que llega a Alma y se le desencaja. Alma vuelve la cara...A Pascuali le alarma la conmoción reflejada en el rostro de Raúl.

-¿Qué le pasa?

Güelmes está al quite.

-Es la emoción. Es la primera vez que ve a su cuñada. Y se parece tanto a su mujer.

Carvalho toma la iniciativa. Coge a Alma por un brazo y por la cabeza y la obliga a mirar a Raúl.

-Alma, mira, éste es Raúl. Raúl, esta es Alma.

Raúl mira a Güelmes, a Alma, a Pascuali, a Carvalho. Finalmente sonríe y pregunta con dificultad: 
-¿Qué tal, Alma?

Se acerca a ella, los rostros se aproximan para un beso protocolario, pero cuando los labios de Raúl se depositan sobre la mejilla de la mujer, de la piel emana toda una historia perdida, los ojos de él y de ella están llenos de dolor, se abrazan, se entregan los dos cuerpos a una fusión completa, más allá de la resistencia de las carnes y los esqueletos. Musitan. Eva María. Eva María.

Pascuali no quiere conmoverse. (115-16, énfasis añadido)

En ese mismo episodio Pascuali observa, cambiándose quizá del lado del orden al del desorden al comprobar su propia utilización por el nuevo régimen democrático, que "por lo visto la mierda secreta del poder no desaparece nunca" (117). En otra ocasión, viendo que también el policía investiga uno (en efecto, varios) de sus casos secundarios, Carvalho comenta medio en broma y medio en serio que "el inspector Pascuali y yo somos como hermanos" (162). Por encima de la broma, Pascuali tiene tanta conciencia como Carvalho de la importancia de los casos que tiene entre manos, y experimenta la misma frustración que él al sentirse manipulado por algún titiritero invisible. Sus "emociones...pugnan por hacer estallar los labios, los pómulos, los ojos" (191) cada vez que se enfrenta a la enormidad de lo que investiga y a su incapacidad de ponerle coto: "-...¿Qué me esconden? La historia.... ¿Estoy de su historia hasta los huevos!...iQQuieren que empiece otra cacería?" (104). Cuando Carvalho quema el Club El Aleph - una incursión en la criminalidad que anticipa su sacudida total de cualquier noción de orden social en Milenio Carvalho (2004) - la afinidad entre ambos se dibuja en el desafío silencioso de Pascuali al director de policía, quien "se levanta para realzar su estatura y jerarquía ante Pascuali. -iQuiero al pirómano! ¡Quiero orden! ¡No quiero alterarme innecesariamente por el desorden que usted está permitiendo!" (338).

Si Carvalho y Pascuali terminan figurativamente hermanados, mayor es el vínculo con el policía Vladimiro. En la primera entrevista entre los dos, Pascuali y Vladimiro acaban de sorprender a Carvalho con Raúl, y Vladimiro queda encargado de tomarle declaración. El agente argentino le cuenta entonces al detective español que "mi padre es primo lejano del tuyo. Yo soy Carvalho de tercero o cuarto apellido" (90)-significativamente, no se menciona nunca el primero. De inmediato surge cierta "complicidad" entre ambos: Vladimiro simplemente le pide a Carvalho que le diga "unas cuantas boludeces para salir del paso". La voz narrativa constata-la breve acotación no deja claro si es desde el punto de vista de Carvalho-que "Vladimiro es humano", y desde este momento el policía deja de interferir 
en los movimientos del investigador. Llega hasta a ayudarle a proteger a Raúl, aún antes de que Pascuali entre en el círculo de camaradería. Apostado de vigilancia un día, ve a Raúl visitar a Alma previsiblemente disfrazado de exterminador de ratas, y lo reporta por radio a su compañero como si no lo hubiera identificado. Cuando Pascuali le ordena seguirlo Vladimiro lo alerta con la sirena, y a las inevitables increpaciones del superior responde con "sonrisa morosa y escasamente indagatoria" (151). Por supuesto, si tanto Raúl como Vladimiro son primos de Carvalho, los tres comparten un lazo que comienza por ser literalmente familiar pero adquiere implicaciones mucho más amplias, y nuevamente sus papeles empiezan a fundirse.

En uno de sus contactos secretos, Raúl cita a Carvalho para dejarle saber definitivamente si se queda en Argentina o accede a volver con él a España. Deben encontrarse en un asado familiar "en casa de un tío segundo" (175, énfasis añadido). En la fecha indicada Carvalho acude al lugar, que resulta ser la casa del viejo Favila, padre de Vladimironuevamente no se aclara del todo si éste es su nombre o apellido, y por tanto cuál sería el apellido real del policía. Como Raúl y otros personajes de la novela, Favila es uno más de los tantísimos "hombres ocultos" (199). Vive escondido en un zulo por "si vienen los milicos, los franquistas o cualquier gente armada" (130) — otra fusión de la historia a ambos lados del Atlántico - y sólo sale una vez al año para su asado de cumpleaños (o si ponen un buen partido de fútbol). Raúl no llega a la reunión; sólo envía un mensaje alargando el plazo. Sin embargo, el encuentro será crucial para Carvalho. Conocer a este nuevo pariente y toparse sorpresivamente con Vladimiro le permite una epifanía sobre su lugar en el drama en que ha irrumpido sin demasiada conciencia y al cual ha estado tratando infructuosamente de sustraerse. Su "tío de América" le había encargado indagar el paradero de Raúl "por la memoria de tu padre", y en la casa de Favila éste entra en escena. Curiosamente, la relación familiar exacta entre Raúl Tourón, Vladimiro (¿Tourón? ¿Favila? ¿Carvalho?) y Pepe Carvalho permanece vaga, y parece juntar las líneas paterna y materna. La nuera que le abre la puerta se lo presenta al viejo señor de esta manera: "Es José Carvalho Tourón, un sobrino de Evaristo Tourón, su primo...e hijo de Evaristo Carvalho, hermano de..." (195). Si Evaristo Tourón, tío materno del detective, es primo de Favila, la relación vendría por esa línea; pero Vladimiro le ha dicho antes (ocultándole la conexión Tourón, a pesar de conocerla) que también lleva el apellido Carvalho. El círculo se cierra con la repetición del nombre Evaristo que designa tanto al padre de Raúl como al de Carvalho. Como se narrará 
muchas páginas más tarde, el primero de los tocayos tuvo un papel bastante dudoso en la historia de Raúl, Alma/Berta y Eva María (y por consiguiente en la historia argentina). El segundo es descrito por Favila como un valiente de la dictadura española- "el padre de este hombre fue un héroe que desafió al franquismo" (195)—incluso si los años que pasó en la cárcel fueron, como aclara Carvalho, cinco, y no los cuarenta que equivocadamente le atribuye el anciano (aunque la dictadura de cuarenta años fue ella misma una cárcel, como lo es el zulo en que vive Favila en pleno gobierno de Carlos Menem). Sin embargo, aunque presumiblemente representan polos opuestos, los dos Evaristos comparten toda una serie de funciones en una cadena circular de consanguinidad. Sobre todo, la coincidencia apunta, como las múltiples versiones del relato de Alma, a la imposibilidad de llegar a una verdad singular y clara, y por lo tanto a ninguna noción simple de justicia.

El nombre de cada uno de los tres hijos de Favila establece una concatenación histórica: Rosa por la marxista polaca Rosa Luxemburg, Dolores por Dolores Ibárruri La Pasionaria, Vladimiro por Lenin y Fulgencio "porque así se llamaba mi padre, tu abuelo" (194). Inmerso en este tejido de parentescos ideológicos y ancestrales (criterios de ascendencia que podrían suponerse distintos pero en realidad no lo son), Carvalho casi experimenta la vuelta a casa que poco antes le ha dicho a Alma que siente vedada para él. Así como la evocación de su Rosebud materno partía del recuerdo de sabores (pan y aceitunas), la nueva visión le llega del asado que comparte con la familia de Vladimiro:

Se sienta y come, cada vez más golosamente, más a sus anchas, como si los sabores le permitieran volver a casa. Al cabo de un rato, de un poso de su memoria le acude un festín de boda, en Barcelona, un primo se casaba con una muchacha de servicio, gallegos los dos, años de noviazgo, de ahorros, un festín de pote gallego, carnes con cachelos, empanadas de berberechos. Era el banquete de su memoria infantil, la felicidad de la abundancia y de un extraño momento de relajación vital o quizá mejor decir histórica. La Historia le había marcado la infancia y la vida entre hombres y mujeres ocultos y ahora volvía a sentirse feliz, comiendo, bebiendo sin miedo, contestando preguntas, sobre todo de don Favila. (196)

Al final de la velada, el viejo lo invita a él solo al escondite "en representación de tu heroico padre" (198). Allí le comunica su confianza en que "un día, una nueva generación, descubrirá el viejo y el nuevo desorden y todas estas esperanzas tendrán sentido" (199). Carvalho "asiente" y "se deja sentar", indulgente si no necesariamente convencido 
(es éste otro momento en que falta el poder explicativo del discurso indirecto libre), y terminan cantando juntos himnos de las Brigadas Internacionales. En ese zulo, verdadero Hades, Carvalho - segundo Ulises de la novela - encuentra la súplica de los muertos heroicos y anónimos que le piden un entierro digno, el fantasma de la madre y la historia del padre, la profecía de Teresías que le advierte de la furia de Poseidón. Como Ulises, fracasará en efectuar una restauración.

El intercambio con el padre de Vladimiro suscita un curioso diálogo entre Carvalho y el policía donde aparecen como personajes paralelos de varias maneras:

- [Carvalho:] Usted ha sido la sorpresa de mi vida.

- [Vladimiro:] Mi padre no sabe que soy policía.

- Mi padre murió sin enterarse de que yo había dejado de ser comunista y que mi oficio era el de policía privado.

Vladimiro duda, pero finalmente habla.

-Yo sabía que usted iba a venir, pero no en plena comida. Raúl me encargó que le dijera que por el momento no tiene una respuesta para usted. Volvió a esconderse...

- ¿El enlace de Raúl era usted?

-Es mi primo. Un primo segundo, pero mi primo. ¿Cree que podría volver a mirar a mi viejo a la cara si fuera yo el que lo detuviera?

- ¿Y Pascuali?

-Un policía con un buen par de huevos. (197)

Ambos personajes comprenden que la historia de España y la de Argentina son dos caras de la misma moneda. Ambos protegen a Raúl desde un concepto ético (¿mítico?) de deber familiar e histórico. Cada uno ha ocultado a su respectivo padre la desilusión con las luchas y convicciones de la infancia. Los dos han cruzado una línea que a sus padres les habría parecido inconcebible: aquí la policía y la policía privada (Pascuali incluido) acaban del mismo lado. Ambos actúan a partir de una moralidad que, si bien responde a un mundo en que esos padres no pudieron ya vivir, tiene su origen en ellos: del suyo propio, Carvalho recordará más adelante en la novela que "tenía sentido del ridículo y no abandonó nunca a nadie" (499). Y no obstante, ambos saben ya que el camino a la superación del pasado no necesariamente excluye el pacto - en esta historia habrá varios - pero sí impone la necesidad de estar, en diferentes momentos, en distintos lados de cualquier simple distinción moral.

A pesar de todo esto ni Carvalho, ni Raúl, ni Pascuali y Vladimiro resuelven el único verdadero misterio: el paradero de Eva María, adoptada 
y rebautizada como Muriel por el Capitán tras negociar con el propio Evaristo Tourón, quien renunció tanto a la restitución del trabajo científico de Raúl como a la nieta a cambio de la libertad de su hijo (y, de paso, la de los amigos de su hijo). Aunque Raúl, Carvalho y los policías realizan descubrimientos parciales, en realidad son los oligarcas y los burócratas gubernamentales - el poder - quienes les suministran las verdaderas pistas cuando consideran conveniente que "Pulgarcito" llegue a "la casa del Ogro" (432). En un principio el millonario Joaquín Gálvez, transformado tras la muerte de su hijo menor en las Malvinas en un Robinsón Crusoe socialista utópico, decide asistir a Raúl porque hacerlo le provee la oportunidad de actuar en contra de su antigua clase (a varios de cuyos miembros chantajea). Más adelante le ayuda Richard, el hijo mayor de Gálvez, para vengar el asesinato de su padre por orden del financiero Ostiz, a quien Robinsón había identificado como implicado en el secuestro y la subsiguiente adopción de Eva María/Muriel. Sin embargo, quien finalmente conduce a Raúl hasta la niña es su antiguo amigo, el ahora ministro Güelmes, trabajando en conjunto con el director de la Policía, Morales. En principio, lo hace en nombre de su antigua camaradería: "Ese hombre es Peter Pan. No creció. Yo tampoco crecí del todo. Por eso lo protejo" (404). Esta motivación no queda del todo desacreditada al final de la novela. Sin embargo, también lo hace para consolidar su poder estatal sin el estorbo de residuos de otra época como es el Capitán. Habiendo pactado con el mismo militar que lo torturó una sociedad civil y económica basada en el robo de la propiedad intelectual de Raúl, ahora opina que "los milicos...ya no son necesarios" (404-05). Manipula a los varios implicados en la trama para que Raúl recupere a su hija y sea ahora el Capitán quien tenga que desaparecer.

El mapa moral del argumento tendría que ser claro: los malos son los secuestradores, torturadores y asesinos, así como aquellos que han pactado con ellos en aras de una supuesta concordia democrática (Evaristo Tourón, Güelmes, hasta cierto momento Font y Rius). No obstante, como ya se ha ido viendo, la novela se abstiene de predicar una claridad moral absoluta. Por un lado, incluso los personajes más monstruosos exhiben cierta complejidad. Las múltiples escenas entre el Capitán y su hija Muriel no dejan duda de que la ama (y ella a él). Es un detalle asombroso que conserve por más de veinte años junto a la cama de la chica la cajita de música que le había regalado de bebé el rockero Pignatari, otro de los amigos subversivos: "El Capitán abre una caja de música. La cajita de Eva María, presente en el recuerdo de Alma" (127). Preservándola, ha preservado también cierta conexión al pasado de la chica. 
En esta cita, la caja de música actúa además como vértice gramatical entre el Capitán y Alma (o más bien Berta) - a quien varias veces en la novela se llama "la Capitana" (501) — estableciendo cierta trabazón entre ellos. De hecho, Alma odia su anterior identidad precisamente por tener conciencia de ese lazo: si no por haber empujado a todos sus amigos a un activismo suicida, tal vez porque en el momento del allanamiento fue militante antes que madre. El Capitán mismo sugiere vagamente incluso un contacto sensual-sentimental entre ellos durante la prisión de Alma: “¿Te acordás cómo llegamos a intimar? ¿Te acordás cuántas veces mi voz te consoló en aquellos momentos tan delicados?" (98). Se refiere muy probablemente a haberla violado, pero aún así los términos que utiliza apuntan hacia uno de los sentimientos más incomprensibles para la generalidad de las personas: una especie de vínculo afectivo entre víctima y captor. La ruptura de la frontera impermeable entre estos dos roles reaparece humorísticamente cuando Carvalho "padece un ataque de síndrome de Estocolmo" (265) ante la botella entera de Glenmorangie 20 años que le sirven precisamente en el Club El Aleph. De forma más siniestra, se ve en el pasaje en pretérito donde Raúl recuerda una ocasión en que el Capitán en persona lo llevó al cine "y a los pocos minutos él y su torturador reían, en un descanso de sus papeles reales" (49).

Esa memoria de Raúl incluye además la pregunta que le hacía el Capitán antes de aquellas salidas: “¿A quién matarías, hijo de puta, por asomar la cabeza al exterior?". La respuesta implícita es que el terror corrompe a la víctima y la convierte en cómplice del agresor, y nadie mejor que Raúl sabría esto porque era precisamente la materia de sus estudios sobre la "memoria biológica" (45) de los animales, mucho más interesante en palabras de su socio original "que la memoria histórica de los hombres". Esos conocimientos lo llevan de haber sido alguien a quien "los supervivientes le parecían sospechosos" (36) a reconocer, sabiendo ya el pacto hecho por su padre, que éste "sólo es, como yo, un superviviente. He tardado en darme cuenta. Apenas nacemos deberían inculcarnos: sos un superviviente, hijo de supervivientes" (406). En efecto, Raúl reconoce que entre el verdugo y la víctima se encuentra la "rata" que actúa desde el instinto primario de sobrevivir, y tal vez por eso repite casi literalmente el pacto de su padre, que tanto daño le hizo. Cuando "la esfinge" (447) enviada por Güelmes le constata que su hija "está en manos del capitán Doreste que usted conoció como Gorostizaga, Ranger en el argot milico" y Raúl le pide evidencia para poder reclamarla, la condición es que "las pruebas dependen de un acuerdo". Raúl contesta sin vacilar que "estoy dispuesto a llegar a cualquier acuerdo que me devuel- 
va a mi hija" (447) y acto seguido accede a que se oculte el papel en la trama del implacable Ostiz, quien todavía piensa que "queda demasiada gentuza que debimos exterminar" (468). Por todo esto, en el careo final con don Evaristo que éste califica como "el Juicio Final" (501), después de escuchar el testimonio de su padre Raúl lo absuelve con palabras que recuerdan más las de Jesucristo a la mujer sorprendida en adulterio que el Apocalipsis del Antiguo Testamento: "Nadie te juzga" (502).

No hay justicia al final de Quinteto de Buenos Aires, si por ella puede entenderse el castigo de los criminales de guerra pretendido por autoridades como Baltasar Garzón, de quien Güelmes se ha mofado muy temprano en la novela: “¡La ONU! ¡Amnesty! ¡La madre Teresa de Calcuta! ¡El juez Garzón! ¿No se llama Garzón ese juez español que quiere encarcelar a toda la Junta Militar del Proceso? ¿Y nuestra soberanía? Somos los dueños de nuestros torturadores y hemos decidido perdonarlos" (120). Güelmes es ministro en ascendencia, Ostiz quedará impune y el Capitán huye a Paraguay, donde inmediatamente le proporcionan una pistola, un pasaporte y un nuevo nombre que tal vez haya sido ya uno de los muchos que ha tenido- "siempre me gustó llamarme Juan Carlos" (514) - y que curiosamente es el mismo del entonces Rey de España (país que también decidió perdonar a sus torturadores). Tampoco hay justicia si se entiende por ello restitución para los que sufrieron. Ni siquiera Alma y Raúl recobran de verdad a su hija, algo ya sobreentendido durante la conversación en que planifican junto con Norman y Font y Rius el encuentro con la chica. No se sabe quién dice qué en el diálogo correspondiente, pero el mensaje es evidente: "- ¿La llamamos Eva María? -Me gusta más Muriel. -Que se llame como ella quiera" (504). Eva María (Telémaco) ya no existe y, apropiadamente, el reencuentro de Alma y Raúl con su hija es un total anticlímax. Se unen a la chica en una manifestación de estudiantes, y ella los recibe con cierta distancia y quizás hasta suspicacia: "Muriel los ha visto llegar muy seria...Ella ha mirado a Raúl con mucha curiosidad. Ha dicho: lo sé ya todo. Pero no ha añadido nada. Caminan y caminan, mirándose de reojo" (506). Como dice Norman, en realidad aunque llegue a saber todo sobre sus orígenes, "Muriel nunca será normal" (505). Nunca será simplemente la hija recuperada de Alma y Raúl, puesto que seguirá siendo la hija del Capitán, a quien amaba y con cuya culpa, aunque sea imposible la reconciliación, deberá conciliar ese amor como Raúl hubo de conciliar los actos de don Evaristo y los suyos propios. Es significativo, sin embargo, que la marcha en que se encuentran conmemora la Noche de los Lápices, una matanza de estudiantes adolescentes considerados subversivos que tuvo 
lugar en 1976, muy cerca de la fecha en que Muriel fue robada a sus padres. Si algún optimismo por la justicia tiene la historia que la novela cuenta, es la aparición de una nueva generación de jóvenes literal y figuradamente "aparecidos" que tal vez tomen el relevo de los que desaparecieron sin remedio. En otras palabras, lo que soñaba Favila, el viejo comunista vencido que encarna la figura del padre: "un día, una nueva generación, descubrirá el viejo y el nuevo desorden y todas estas esperanzas tendrán sentido".

Carvalho acompaña a los otros a buscar a Muriel y participa en la marcha "junto a desconocidos entusiasmados por su propia capacidad de desafiar al demonio del olvido" (506), pero no se queda para el momento de la reunión familiar. Ya no es parte del quinteto, y su labor como detective en el caso Tourón-Modotti también ha sido relativamente infructuosa: no fue él quien finalmente llegó a su solución, y ni siquiera parece que llegue a conocer algunos pormenores. Por ejemplo, cuando almuerza con Gálvez hijo y Ostiz y ve que el primero parece olvidarse de vengar a su padre cuando quien lo asesinó le ofrece construir en su nombre un lucrativo parque de atracciones, finalmente decide "que el viejo Gálvez era el padre de Richard, no el suyo" (276) y deja de lado el tema. No se enterará cuando Gálvez ponga a Raúl tras la pista de Ostiz y el Capitán. Y sólo después de haber partido hacia Barcelona se dará cuenta de cómo se desenredó la madeja:

“Fallece en accidente aéreo Richard Gálvez"...Y de alguna reserva de ingenuidad le sube una bocanada de angustia hasta que la convierte en aire. La muerte de Richard Gálvez. La facilidad repentina con la que todos habían llegado a Muriel, la caída del Capitán. Hubiera dado la vuelta al avión de regreso a Buenos Aires...El poder. Sin duda había intervenido el poder real para facilitarse las cosas a sí mismo. (521)

Si bien es frecuente que los finales de las novelas de la serie no acarreen la restauración de ningún orden, lo que llama la atención en este caso es la posición casi tangencial de Carvalho en la resolución del misterio. En un guiño irónico a Doyle, es Don Vito quien le responde a él en cierto momento: "elemental" (136). Mucho más importante que su papel como investigador parece el proceso emotivo por el que pasa. Si el concepto de memoria histórica puesto en acción en la España posterior a la transición parece derivar su función "terapéutica" de una operación tan cercana finalmente a una "science of deduction and analysis" como es recordar y ordenar, recuperar los cuerpos perdidos y castigar los crímenes de la dictadura - ejercicios que permiten el duelo-la educación sentimental de Carvalho en Quinteto parece acercarse más a nociones 
clásicas de la catarsis. En este sentido la posible purificación ética y estética del yo parte no sólo de abrirse a las emociones propias, sino de la compasión y el terror provocados por la apertura a la tragedia del otro.

Como producto de la estructura novelística, el cambio del foco de atención de los razonamientos del detective a su trayectoria sentimental tiene un recurso complementario en la presencia de la música en Quinteto de Buenos Aires, evidentemente desde su mismo título. No es la primera obra en que Vázquez Montalbán utiliza la música como espina dorsal de la exploración de un proceso a la vez emotivo y político. Esta relación interartística tiene muchas variantes y funciones en su obra, y sus manifestaciones particulares en Quinteto merecen estudio aparte. Puede advertirse, a vuelo de pájaro, que las múltiples duplicaciones y desdoblamientos anteriormente analizados pueden ser vistos como estrofas, estribillos, puentes musicales, solos que cobran significado precisamente a través de su interacción-presentando temas, alejándose de ellos, repitiéndolos, conectándolos con otros de formas que no siguen una lógica verbal. Por otro lado, la noción de quinteto y su sugerencia de una pieza musical interpretada en conjunto apunta (al menos) en dos direcciones: a la experiencia compartida y dinámica de los protagonistas varios, cuyo papel en la trama evoluciona a lo largo de la novela; y a la combinación y recombinación de las fuerzas del poder para perpetuarse a lo largo de regímenes distintos.

Una conexión a la cual sí interesa llamar la atención en el contexto que nos ocupa es con la Crónica sentimental de España (1971), donde el comentario del cancionero popular desde los años 40 hasta los 60 funciona como alternativa a la historia oficial promulgada desde el franquismo trazando una "nueva sentimentalidad" desde el presupuesto de que "en cuanto resonancias cordiales de los valores en boga, los sentimientos varían cuando estos valores se desdoran, enmohecen o son sustituidos por otros" (Crónica 9). Ese texto enfatiza la letra de las canciones (aunque al final éstas ceden paso al silencioso ritmo go-go) como testimonio de los deseos, miedos, placeres y dolores de individuos y comunidades marcados por la represión, y el ejercicio de esos sentimientos a través de la música popular como acto de disconformidad con el limitado repertorio vital aprobado por el régimen. Algo parecido pasa en Quinteto: como explica Carlos Pardo en su artículo "La novela de detectives y la música", la novela emplea este tipo de "verbal music" (148) como "compañera y guía" (149) que ilumina las experiencias de los personajes. Quinteto de Buenos Aires comienza y termina con tango, desde el "Corrientes, 348" de la llegada hasta el "Volver" del final (ya aludido por 
Vázquez Montalbán en Pero el viajero que huye de 1991) cuya letra entera, aunque la novela sólo incluya un verso, parece resumir el dilema de Carvalho: "tengo miedo del encuentro con el pasado que vuelve". Ya nota Alma que sus preferencias musicales (bolero, corrido, tango) son sobre todo composiciones verbales: "Te gustan más las palabras que los cuerpos. El rock es una música para el cuerpo, las que vos decís están llenas de palabras" (Quinteto 75). Entre las dos canciones bookend encontramos múltiples letras de tangos reales o compuestos por el mismo Vázquez Montalbán que aluden a las aventuras del argumento, e hiladas van trazando el camino que recorre Carvalho. Cerca del principio, por ejemplo, aparece implícito su papel de detective tras las huellas de algo que ya se ha esfumado: "Buscás / las sombras de un recuerdo, / pisadas en la sangre / antigua como el sol...Pasá extranjero, / no hay piedad / para quien perdió / el tren del tiempo" (124). Y en su última visita al local Tango Amigo la alusión a la dualidad Barcelona/Buenos Aires, a las guerras, a lo imposible de la pesquisa:

Doce guerras, doce esquinas, doce puertas,

doce infiernos...

Mas si desciendes a la ciudad rendida

donde moran las sombras de todo lo que vive..

si desciendes no reconocerás sombra alguna

ni serás reconocido por sombra alguna,

ni ésta es tu casa aunque tu casa fuera

una aproximada maqueta de esta ruina,

la maltratada tumba de tu olvido.

Recuerda la nada y su paisaje,

tus cuatro horizontes protegidos:

no se debe, no se sabe, no se puede, no se vuelve. (510)

Sobre todo, el recurso al tango en general-un género musical tan asociado al despliegue de lo sensual como baile y de lo pasional como letra - acentúa la instrumentalidad (en todos los sentidos del término) de lo emocional en la trayectoria seguida por Carvalho en la novela. Habría que añadir que, en esta función, las canciones también cumplen un papel que se acerca bastante al de los coros de la tragedia clásica, comentando la acción pero también interpelando directamente a Carvalho.

La letra de este último tango, original de Vázquez Montalbán por supuesto, reitera el tema del viaje de Ulises, la más visible de todas las referencias literarias de la novela. Es claro que la jornada sentimental de Carvalho por Buenos Aires es un proceso de asimilación cultural, pero 
también tremendamente personal, de las huellas de la dictadura y la transición. No obstante, es absurdamente fácil, si el lector de Quinteto se concentra demasiado en la trama principal, no darse cuenta de que la novela - como La odisea - es una historia de padres e hijos o, tal vez, como dice Carvalho mismo, de "familias imposibles" (127). Raúl vuelve a Argentina en busca de su hija Muriel, y en el proceso se refleja en su propio padre, que la abandonó. Alma, por supuesto, reproduce la misma búsqueda. Pero también los casos y personajes intercalados repiten la temática, siempre sin resolución satisfactoria. La paternidad incierta en el caso de Arielito, quien busca ser reconocido como el hijo natural de Borges para mantener a su madre, antigua contorsionista, y termina olvidándose de padres fingidos y haciéndose pasar por el tanguista Goyeneche. El caso de la mala mujer con quien ha desaparecido el hijo de un rico comerciante, y que acaba siendo amante del mismo padre. La tragedia del boxeador Bum Bum Peretti, cuyo lugar en la cultura argentina requiere que codifique sus relaciones homosexuales - con su maestro Loaiza, con el joven Bruno-como paternofiliales, y quien termina suicidándose en su avioneta cuando el primero de los dos es asesinado. La muerte del Gran Gratowsky que cincuenta años antes abandonó a su hija, cuyo drama personal afecta la perspectiva de Carvalho: "Por los ojos de la mujer pasa la película de un sueño, y Carvalho de pronto se siente triste, conmovido. Masculla una disculpa y se va" (499). El deseo de Joaquín Gálvez de vengar en su clase social la muerte de su hijo en las Malvinas, y el igualmente fracasado deseo de Richard Gálvez de vengar la de su padre Joaquín (ambos son asesinados por órdenes de la oligarquía y el poder - el segundo en un falso accidente aéreo que recuerda la muerte de Peretti). Todas estas genealogías interrumpidas refuerzan la importancia de la visita al zulo de Favila, donde Carvalho reconecta con su propio linaje y tal vez encuentra algún sentido a su propia trayectoria. $\mathrm{Y}$ todas cobrarán significación añadida cuando sepamos, al leer Milenio Carvalho (la odisea de un viaje de Carvalho y Biscuter alrededor del mundo), que Carvalho tuvo una hija a quien vio por última vez décadas antes, con una mujer llamada precisamente Muriel. Al final de Quinteto, de camino a Barcelona, Carvalho nos da noticia - en lenguaje de tangode que reemprende el viaje a Ítaca: "Pero el viajero que huye, tarde o temprano detiene su andar"'. Lo que encontrará en un mundo que todavía es todo tango, desaparecidos y Maradona (con Expediente $X$ ahora de por medio) lo veremos en las dos siguientes y últimas novelas.

En Quinteto de Buenos Aires, sin embargo, la educación sentimental de Pepe Carvalho ha cumplido un cometido político. En su artículo "Are 
Emotions a Kind of Practice?", Monique Scheer postula que las emociones, tradicionalmente consideradas un fenómeno puramente individual y físico, son una práctica social, "an act situated in and composed of interdependent cognitive, somatic, and social components. . .They are an action of a mindful body" (219-20). Los medios de comunicación-la literatura incluida - pueden ponerlas en escena o mobilizarlas para tener un efecto real, "for personal as well as social purposes" (211). En la misma línea, en su libro The Navigation of Feeling Walter Reddy propone el concepto de emotive - una enunciación emocional que "traduce" para la conciencia cosas que se suelen sentir inconscientemente, y mediante el proceso de darles nombre tiene "self-altering effect" (101), y por extensión efecto social. Tales enunciados le proveen al sujeto la posibilidad de conducirse y reconducirse según evoluciona su autoconciencia, en ejercicio de lo que Reddy llama "emotional liberty" (122). La libertad emocional, por su parte, es un arma del individuo dentro de un régimen emocional:

Central to the life of individuals, open to deep social influence, emotions are of the highest political significance. Any enduring political regime must establish as an essential element a normative order for emotions, an "emotional regime"... At one extreme are strict regimes which require individuals to express normative emotions and to avoid deviant emotions. In these regimes, a limited number of emotives are modeled...Individuals are required to utter these emotives in appropriate circumstances, in the expectation that normative emotions will be enhanced and habituated. Those who refuse to make the normative utterances (whether of respect for a father, love for a god or a king, or loyalty to an army) are faced with the prospect of severe penalties...The penalties may come in the form of torture, aimed at extracting a change through induced goal conflict, or in the form of simple violence, confinement, deprivation, exile. (124-25)

Tanto las dictaduras española y argentina como las democracias triunfalistas basadas en la recombinación del poder son regímenes que dependen de la regulación emocional, algo de lo que el Capitán tiene plena consciencia cuando hace comentarios como: "Mis sentimientos son personales e intransferibles. En cuanto transferís tus sentimientos [a otros], se convierten en obscenos" (457). Consciente de que el verdadero problema de fondo no son necesariamente los pactos de olvido sino la continuidad de regímenes de poder que no pueden ser olvidados porque en realidad no se han acabado del todo, el sujeto contestatario - Carvalhofinalmente sólo puede recuperar, no los cuerpos aparecidos ni los enterrados, sino los sentimientos. La larguísima serie de emotives que Váz- 
quez Montalbán despliega en la novela permite a sus personajes subvertir, aunque sea de forma provisional, el régimen de la violencia física, económica y política: si los sentimientos son "resonancias de los valores en boga", la práctica de emociones que el poder ha buscado reprimir tiene la capacidad de revertir esos valores. La perturbación de la normalidad aparente, el sufrimiento al desnudo, la ternura, la complicidad, la furia incluso hasta la explosión (literal en esta novela) — en fin, la construcción de una nueva sentimentalidad - son formas de resistencia que afirman la humanidad y tal vez algún día puedan llevar a construir un nuevo régimen.

\section{Bibliografía}

Bergero, Adriana J. Intersecting Tango: Cultural Geographies of Buenos Aires, 1900-1930. Pittsburgh, U Pittsburgh P, 2008. Impreso.

Bradshaw, Peter. "Citizen Kane and the Meaning of Rosebud." The Guardian $25 \quad$ April 2015.2 Web. https://www.theguardian.com/film/2015/apr/25/citizen-kane-rosebud

Chandler, Raymond. "The Simple Art of Murder." The Simple Art of Murder. Boston: Houghton Mifflin, 1950. 519-33. Impreso.

Colmeiro, José. Crónica general del desencanto: Vázquez Montalbán Historia y ficción. Barcelona: Anthropos, 2014. Impreso.

Doyle, Arthur Conan. A Study in Scarlet and The Sign of Four. Londres: John Murray, 1903. Impreso.

García Oliveri, Ricardo. "Resucita la miniserie de Carvalho." Clarín 3 de noviembre, 1997. Web. http://www.clarin.com/diario/1997/11/03/c00301d.htm

Jaramillo, Ana. Tango: Tratado de las pasiones. Buenos Aires: Ediciones de la Universidad Nacional de Lanús, 2010. Impreso.

Pardo, Carlos. "La novela de detectives y la música. El caso del Quinteto de Buenos Aires de Manuel Vázquez Montalbán". Polifonia 3.1 (2013): 148-166. Web. https://www.apsu.edu/polifonia/v3/2013pardo.pdf.

Reddy, William M. The Navigation of Feeling: A Framework for the History of the Emotions. Cambridge: Cambridge UP, 2001. Impreso.

Scheer, Monique. "Are Emotions a Kind of Practice (And Is That What Makes Them Have a History)? A Bourdieuian Approach to Understanding Emotion." History and Theory 51 (2012): 193-220. Impreso. 
Song, H. Rosi. "Resolviendo crímenes al otro lado del Atlántico: El viaje de Carvalho a Latinoamérica." Hispanic Journal 23 (2002): 173-84. Impreso.

Vázquez Montalbán, Manuel. "Adriana Varela: o tango o cocaína. Dúo con la tanguista de Quinteto de Buenos Aires", El País (8 febrero 1998). Web.

---. Crónica sentimental de España. Barcelona: Lumen, 1971. Impreso.

---. Milenio Carvalho. Barcelona: Planeta, 2004. Impreso.

---. El premio. Barcelona: Planeta, 1996. Impreso.

---. Poesía completa. Memoria y deseo (1996-2003). Barcelona: Península, 2008. Impreso.

---. Quinteto de Buenos Aires. Barcelona: Planeta, 1997. Impreso.

Welles, Orson. Citizen Kane. New York: Mercury Theater for RKO Radio Pictures Corp, 1941. 